\title{
Xu hướng ứng dụng Công nghệ trong Giáo dục: Cải tổ toàn diện vì một thế hệ người học mới
}

Hoàng Anh Đức1

EdLab Asia

Email:duc@edlabasia.org

Bài đăng trên Tuổi trẻ Cuối tuần, số ra ngày 05 tháng 01 năm 2020

Xuất bản online ngày 10 tháng 01 năm 2020

Nguồn URL: https://cuoituan.tuoitre.vn/tin/20200110/xu-huong-ung-dung-cong-nghe-trong-

giao-duc-cai-to-toan-dien-vi-mot-the-he-nguoi-hoc-moi/1550658.html

Thế giới đang bước sang thập niên 20 của thế kỷ XXI. Khi các thói quen, đặc điểm của giới trẻ centennial (thế hệ Z, sinh từ 1996 2011) vẫn còn đang được dần dần hé lộ, giới nghiên cứu đã phải hết sức vội vã bởi sự tiếp nối của thế hệ Alpha ( $\sinh$ từ 2011 2025). Khi trẻ em sinh ra đã được bủa vây bởi công nghệ, nhu cầu về ứng dụng công nghệ trong học tập không chỉ dừng lại ở công cụ lưu trữ, giao tiếp hay cộng tác thông thường mà trở nên bao trùm và xoá nhoà ranh giới giữa học tập, giải trí và việc thể hiện lối sống. Thêm vào đó, nhu cầu học tập của các thành phần xã hội khác cũng liên tục góp phần đặt ra các yêu cầu mới việc ứng dụng công nghệ trong giáo dục.

\section{Tốc độ, chi phí và nhu cầu}

Người dùng có thể lựa chọn sử dụng một công nghệ bất kỳ phù hợp với nhu cầu của mình, hoặc phải sử dụng một số công nghệ mà tổ chức, trường học quy định bắt buộc. Dù con đường nào đưa chúng ta đến với một sản phẩm công nghệ, thì chúng ta vẫn tiếp cận chúng dựa theo chức năng (xử lý dữ liệu, văn bản, thuyết trình, thiết kế...) hay theo mục đích (để học, để luyện tập, để thực hành hoặc mô phỏng). HolonIQ (Công ty hàng đầu thế giới về nghiên cứu thị trường trong lĩnh vực Edtech) đã dự báo mức độ tăng trưởng đầu tư từ 2018 đến 20252 cho các nhóm công nghệ trong giáo dục như sau: $\mathrm{AR} / \mathrm{VR}$ từ 1,8 tỷ lên 12,6 tỷ USD; AI từ 0,8 tỷ lên 6,1 tỷ USD; Robotics từ 1,3 tỷ lên 3,1 tỷ USD; và Block-chain từ 0,1 lên 0,6 tỷ USD. Về cơ bản, bên cạnh hai trụ cột chức năng và mục đích, các đổi mới về công nghệ trong giáo dục sẽ có xu hướng xoay quanh cải thiện sự tinh vi của các thuật toán $(\mathrm{AI})$, và kèm theo đó là sự nâng cấp trải nghiệm người dùng (AR/VR).

Không chỉ các gã khổng lồ công nghệ như Facebook hay Google mới thúc đẩy xã hội tiến tới thời đại mới của khởi nghiệp điện toán (Vuong, 2019)3 và nhìn vào mỏ vàng dữ liệu người dùng để tối ưu hoá doanh số. Nhu cầu phân tích dữ liệu thời gian thực đã trở nên căn bản đối với các tổ chức giáo dục, ít nhất để phục vụ các mục đích cơ bản của quá trình học tập (học, luyện tập, kiểm tra). Trong quá trình tương tác với các học liệu qua các giao thức công nghệ, người học để lại những "dấu chân kỹ thuật số" về năng lực, hành vi và xu hướng học tập của mình. Quá trình phân tích các dấu vết đó giúp cả người học, người dạy hiểu hơn về trải nghiệm học tập của từng cá nhân, từ đó có những điều chỉnh chủ động về hành vi, phương thức và mục tiêu học tập, bên cạnh những điều chỉnh do máy tính gợi ý và âm thầm thực hiện. Không chỉ

1 Trưởng nhóm Nghiên cứu Học và Dạy, Trung tâm Nghiên cứu và Phát triển Giáo dục EdLab Asia 2 https://www.holoniq.com/edtech/10-charts-that-explain-the-global-education-technologymarket/

3 Vuong, Q. H. (2019). Computational entrepreneurship: from economic complexities to interdisciplinary research. Problems and Perspectives in Management, 17(1): 117-129. doi:10.21511/ppm.17(1).2019.11 
giới hạn ở phạm vi học thuật với các ứng dụng gia sư hay luyện thi, các ứng dụng công nghệ còn hỗ trợ việc cải thiện cảm xúc và các hành vi xã hội, cũng như mở rộng đến cả giai đoạn phát triển đầu đời của trẻ (0 6 tuổi).

Sự chuyển hoá về hành vi và nhu cầu sử dụng công nghệ không chỉ dừng lại ở cấp độ cá nhân, mà còn diễn ra ở cả quy mô tổ chức. Chỉ đôi ba năm trước, các hệ thống quản trị nhà trường vẫn còn được đặt trong vòng nghi hoặc. Chỉ một số trường đại học cấp tiến tự xây dựng các hệ thống quản trị nhà trường của riêng mình, một số bắt tay với các đơn vị cung cấp nền tảng để mở rộng thị phần đào tạo từ xa, còn đại đa số các trường phổ thông chỉ tiếp cận một cách thụ động hoặc có phần gượng ép các giải pháp do cơ quan chủ quản gợi ý. Các nhà quản lý giáo dục ngần ngại chuyển đồi bởi chi phí đầu tư khổng lồ, chưa hiểu rõ về giải pháp, cũng như chưa sẵn sàng cho các thay đổi có hệ thống. Giờ đây, thay vì phải đầu tư đồ sộ vào các hệ thống máy chủ, các cơ sở trường học có thể thuê các máy chủ ảo và cài đặt các hệ thống phần mềm mã nguồn mở. Việc nhất quán các giao thức về cơ sở dữ liệu cũng giúp các trường tự chủ hơn trong việc lựa chọn giải pháp mà vẫn đảm bảo thống nhất được tiêu chuẩn quản lý dữ liệu mà cơ quan chủ quản đề ra (nếu có).

Nối bước các dự án "Tin học hoá nông thôn" vốn chỉ tập trung vào việc trang bị cơ sở vật chất, các thiết bi phần cứng đã đi vào dĩ vãng, các dự án đào tạo giáo viên sử dụng một bộ công cụ XYZ nhất định cũng sẽ mau chóng lỗi thời. Giờ đây, để hoàn thiện một poster thuyết trình cho đề tài khoa học, học sinh không cần phải thành thạo một phần mềm thiết kế chuyên nghiệp như Photoshop mà có thể lựa chọn giữa hàng loạt các giải pháp thiết kế tự động hoặc kéo thả đơn giản, trực tuyến và miển phí. "Trực tuyến" và "Miễn phí" - hai từ khoá tưởng chừng đơn giản, nhưng đã thay đổi cuộc chơi công nghệ một cách mãnh liệt. Khi có nhiều lựa chọn giá rẻ hoặc miễn phí, chi phí thay đổi giữa các giải pháp không còn là điều đáng để bận tâm nên người dùng cá nhân hoàn toàn có nhiều quyền chọn lựa hơn. Cũng bởi vậy, mỗi cá nhân cần phát triển năng lực học hỏi và làm chủ cái mới, trong khi bài toàn dành cho các nhà phát triển là tìm kiếm, nắm bắt và thậm chí kiến tạo nên nhu cầu mới.

\section{Cá thể hoá trải nghiệm học tập}

So với thế hệ milenials (thế hệ Y, sinh từ 1981 1996), thế hệ centennial (thế hệ Z, sinh từ 1996 2011) có những bùng phát mạnh mẽ hơn về nhu cầu thể hiện bản thân. Các tiếp cận mang tính cải tổ trong thập niên trước như giảng dạy phân hoá (differentiation) và cá nhân hoá giáo dục (individualization) đều lấy giáo viên làm trung tâm để đưa ra những hướng dẫn khác biệt cho từng nhóm học sinh hoặc từng cá nhân có vẻ đang đối mặt với các đặc tính của thế hệ $Z$. Trong bối cảnh ấy, chủ trương cá thể hoá giáo dục (personalization) khuyến khích người học tự điều hướng quá trình học tập quả mình có vẻ trở nên khả thi hơn với sự chắp cánh của công nghệ.

Năng lực tự học đang ngày càng khẳng định tầm quan trọng của mình trong một thế giới đầy biến động. Giáo sư Peter Senge (Trường Quản lý MIT Sloan, tác giả cuốn Kỷ luật thứ năm) cho rằng: "Vũ khí cạnh tranh mạnh nhất là học nhanh hơn đối thủ". Năm 1982, Buckminster Fuller (1895-1983) - Kiến trúc sư, nhà thiết kế và sáng chế nổi tiếng người Mỹ đã từng đề xuất khái niệm Knowledge Doubling Curve (Đường cong mô tả quá trình nhân đôi kiến thức). Ông ước tính rằng đến năm 1900, kiến thức của con người đã tăng gấp đôi sau mỗi thế kỷ, nhưng đến khoảng 1945, nó đã tăng gấp đôi sau mỗi 25 năm, và đến 1982, nó chỉ mất chừng 12 13 tháng để nhân đôi. Hãng máy tính IBM dự đoán rằng tới 2020, như những con sóng thần, kiến 
thức của nhân loại sẽ nhân đôi chỉ sau 11 12 giờ (Biech, 2018)4. Đối diện với cơn sóng thần ấy, từ lâu chúng ta đã nhận ra rằng, bộ não tưởng chừng như quyền năng của chúng ta không thể và không nên tập trung vào việc ghi nhớ. Các công cụ chỉ đơn thuần hỗ trợ việc ghi chép hay lưu trữ thông tin giờ đã trở thành những công cụ vỡ lòng và dần phai nhạt trước sự xuất hiện ồ ạt của các công cụ mới.

Sự trỗi dậy của các công nghệ nhập vai như Thực tế ảo (VR), Thực tế tăng cường (AR) và Thực tế hô̂n hợp (MR) đã dần thu hút và tạo nên được sự chú ý của người học. Thế nhưng, chỉ vui thôi thì vẫn chưa đủ. Việc phát triển các công nghệ này về chiều sâu để có những trải nghiệm học tập thực sự gắn kết và hiệu quả vẫn đang là một khu vườn cần được cày xới, chăm bẵm với sự chú tâm. Ví dụ, ta có thể tham khảo góc nhìn về sự kết hợp hài hoà giữa sư phạm và công nghệ của Punya Mishra và Matthew J. Koehler (2006)5: Mô hình Thiết kế Sư phạm TPACK. Bằng cách phân biệt kiến thức về công nghệ (Technological Knowledge), kiến thức về sư phạm (Pedagogical Knowledge) và kiến thức về nội dung (Content Knowledge), TPACK lưu ý giáo viên việc cần làm trước khi lựa chọn một giải pháp công nghệ. Bản thân quá trình phác thảo nội dung (những gì được dạy) và phương pháp sư phạm (cách giáo viên truyền đạt nội dung đó) mới là nền tảng để công nghệ giáo dục được triển khai một cách hiệu quả, thay vì để nội dung và phương pháp bị lệ thuộc vào công nghệ, chỉ vì đó là một công nghệ có vẻ mới mẻ và hào nhoáng.

Các trải nghiệm học tập có thể diễn ra một cách đồng bộ hoặc không đồng bộ. Các hoạt động học tập đồng bộ (Synchronous learning) tập trung đến việc trao đổi ý tưởng và thông tin giữa nhiều người trong cùng một khoảng thời gian (vd: thảo luận trực tuyến, lớp học ảo), yêu cầu sự lắng nghe và học hỏi từ những người khác. Mặt khác, các hoạt động học tập không đồng bộ (Asynchronous learning), người học tiến hành theo tốc độ riêng của bản thân mình để nghe lại một bài giảng, hay để suy nghĩ nhiều hơn về một câu hỏi mà không làm ảnh hưởng đến những người khác. Hiện nay, các nền tảng giáo dục trực tuyến đang có xu hướng trộn lẫn hai dạng thức trải nghiệm học tập này, thay vì chỉ lựa chọn đơn lẻ một trong hai hình thức. Điển hình, có thể kể đến các chương trình Micro-degree của các trường đại học hàng đầu thế giới như MIT, UC Berkeley..., nơi mà người học có thể lựa chọn một môn học mà mình thấy thích thú nhất, hoàn thành nó qua quá trình học tập đan xen đồng bộ và không đồng bộ. Các chứng chỉ Micro-degree không chỉ công nhận việc hoàn thành một số khoá học trực tuyến, mà còn được coi như tấm giấy thông hành tới các chương trình cấp bằng chính thức của các trường đại học kể trên. Theo trang tin EdSurge6, tính đến cuối năm 2018 đã có tới hơn 630 chương trình Microdegree cấp chứng chỉ được kiểm định. Thay vì lựa chọn một chuyên ngành mà mình chưa hiểu rõ và có nguy cơ bỏ giữa chừng, người học quyết định học những gì mình thích, dần làm rõ đường hướng và củng cố kiến thức về chuyên ngành đó. Sự đảo ngược hành vi chọn lựa này sẽ đem lại áp lực không nhỏ cho các trường đại học nhỏ, hoặc các nền tảng học tập đại học trực tuyến thông dụng.

\section{Công nghệ và Xã hội học tập}

HolonIQ đã liệt kê tới 55 nhóm sản phẩm công nghệ giáo dục khác nhau, chia thành 11 mảng, bao gồm: Tri thức và nội dung; Quản trị Giáo dục; Các mô hình giảng dạy truyền thống; Các

\footnotetext{
${ }^{4}$ Biech, E. (2018). ATD's Foundations of Talent Development: Launching, Leveraging, and Leading Your Organization's TD Effort. American Society for Training and Development.

${ }^{5}$ Mishra, P., \& Koehler, M. J. (2006). Technological pedagogical content knowledge: A framework for teacher knowledge. Teachers college record, 108(6), 1017-1054.

${ }^{6} \mathrm{https}$ ://www.edsurge.com/news/2019-02-26-much-ado-about-moocs-where-are-we-in-theevolution-of-online-courses
} 
mô hình giảng dạy mới; Học tập trải nghiệm; Giáo dục Quốc tể; Hỗ trọ học tập; Đánh giá và Kiểm chứng; Nguồn nhân lực và Tài năng; Kỹ năng và Nghề nghiệp; Các úng dụng hô̂ trợ cho hệ sinh thái Edtech.

\section{Global Learning Landscape}

\section{Holon $1 \mathrm{O}$}

An open source taxonomy for the future of educotion. Mopping the leorning and talent innovation landscape.

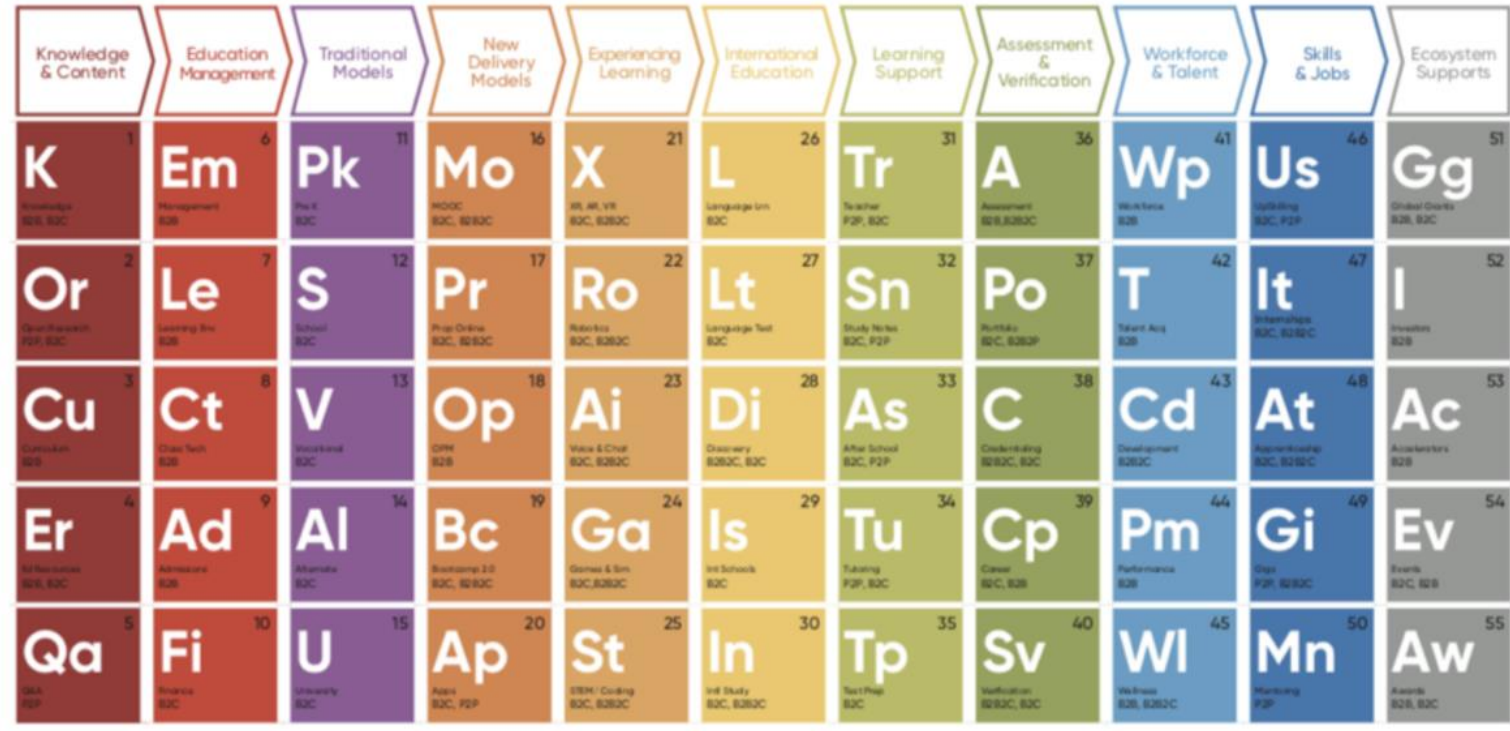

Các loại hình sản phẩm Công nghệ úng dụng trong Giáo dục (HolonIQ, 2019).

Về cơ bản, ranh giới của các mô hình học tập truyền thống gần như không còn ý nghĩa chi phối khi công nghệ quản lý và hỗ trợ học tập đã vượt ra khỏi khuôn khổ trường học và tạo ra những thói quen học tập mới. Tất nhiên, trong lĩnh vực giáo dục phi chính quy, các công nghệ giáo dục cũng không thể tránh khỏi ảnh hưởng của các cuộc đua về chi phí và trải nghiệm người dùng. Đối với các doanh nghiệp, yếu tố chi phối không chỉ đơn thuần là thị hiếu của người dùng mà còn là áp lực của thị trường. Kết quả học tập của một cá nhân học sinh chỉ ảnh hưởng tới bản thân học sinh đó, nhưng hiệu suất học hỏi và phát triển của từng cá nhân trong doanh nghiệp đều mang ý nghĩa sống còn đối với cả doanh nghiệp. Trước áp lực đó, nhu cầu về phát triển nguồn tri thức trong các doanh nghiệp (learning and development) đang ngày một rõ nét. Giải pháp micro-learning với các bài học ngắn gọn và súc tích (chỉ kéo dài khoảng 2 5 phút) giúp cho việc học được diễn ra tinh gọn hơn, hay các hệ thống quản trị tri thức, các hệ thống tổ chức nhóm học tập trực tuyến đã dần trở nên quen thuộc.

Bản chất của hoạt động giáo dục là quá trình tự trưởng thành qua việc học. Trong các làn sóng cải tổ công nghệ, bất kể bối cảnh nằm ở các nhà trường, doanh nghiệp hay xã hội thì vai trò của công nghệ vẫn luôn là thứ yếu. Bill Gates, nhà sáng lập Microsoft đã từng nói "Công nghệ chỉ là công cụ. Để giúp cho trẻ em công tác tốt và có động lục, vai trò của giáo viên là quan trọng nhất." Vậy nên, hãy để việc học của bạn quyết định công nghệ gì bạn sẽ sử dụng, cũng như cách mà bạn sẽ sử dụng chúng! 